\title{
Clinical Analysis and Management of Long-Stay Patients
}

\author{
Chienhsiu Huang (D) \\ Department of Internal Medicine, \\ Division of Chest Medicine, Dalin Tzu \\ Chi Hospital, Buddhist Tzu Chi Medical \\ Foundation, Chiayi, Taiwan
}

Background: Worldwide, a certain proportion of patients stay for long periods. Reduction of length of stay is a critical intervention to optimize in-hospital resource utilization. Length of stay itself is a reliable quality index for healthcare systems. Interventions to reduce long hospital stays require understanding organizational and individual factors that affect the length of stay. The purposes of this study are to attempt to reduce long stays (defined as $>30$ days) by identifying the causes and preventing such situations.

Methods: This was a retrospective observational study of patients who stayed in the hospital for long periods (>30 days) between 1 January 2018 and 31 December 2018. We identified subgroups of patients with long stays, evaluated their associations with baseline variables, relevant discharge departments, and causes of long stays. We proposed improvement plans. Results: There were 446 long-stay patients (mean age 66.7 years; 37.7\% females), including 158 undergoing prolonged mechanical ventilation, 109 with diseases requiring hospitalization, 93 due to nosocomial infection, 31 with delayed discharge, 20 with iatrogenic complications, and 35 patients with long stays for various causes. There were 9331 hospital days associated with 158 patients with prolonged mechanical ventilation. The number of hospital days for those undergoing prolonged mechanical ventilation was significantly different from that of patients who did not undergo prolonged mechanical ventilation. Depending on the causes of long stay, we could reduce the length of stay in $188(42.1 \%)$ of patients using an aggressive management strategy.

Conclusions: Setting a ventilator weaned unit for prolonged mechanical ventilation patients in a tertiary-level hospital is essential to reduce long stay of intensive care unit. Aggressive management strategies can reduce long stays.

Keywords: long stay, length of stay, respiratory care center, weaning units in acute care hospital

\section{Introduction}

Worldwide, a certain proportion of patients stay for long periods. As the size of the population, age, and care requirements increase, patients who require long stays present increasing challenge to healthcare providers. Reduction of length of stay (LOS) is a critical intervention to optimize in-hospital resource utilization. LOS itself is a reliable quality index for healthcare systems. Numerous studies examined long stays in the pediatric intensive care units, psychiatry wards, and geriatric wards. $^{1-8}$ There were many Chinese articles that discuss patient characteristics associated with long stays in the tertiary-level hospital. The summary of those studies is as follows: Long-stay patients were predominantly male and older than 60. The most common departments for such patients were oncology, chest
Correspondence: Chienhsiu Huang Department of Internal Medicine, Division of Chest Medicine, Dalin Tzu Chi Hospital, Buddhist Tzu Chi Medical Foundation, NO. 2, Min-Sheng Road. Dalin Town, Chiayi County, Chiayi, Taiwan Tel +886-9-21552418

Email hgssport@yahoo.com.tw 
medicine, radio-oncology, general surgery, and orthopedics. The most common disease associated with long stays was a malignancy. These articles did not display detailed analyses of causes and did not offer suggestions to reduce long stays. O'Sullivan reported on the epidemiology of long-stay patients in a university teaching hospital in $2017 .{ }^{9}$ The major findings in this article were as follows: 1) long-stay admissions comprised $13.1 \%$ of admissions but used $49.1 \%$ of bed days; 2) long-stay admissions were often associated with intensive care unit admission, medical emergency team review, and longer duration of mechanical ventilation; 3) factors associated with prolonged stay included multiple admissions during the study period, the nature of the admitting unit, the Charlson comorbidity index at admission, admission from another hospital, and any history of smoking. The paper offered no recommendations for reducing long stays. We aimed to reduce long stays (defined as $>30$ days) by identifying the causes and preventing such situations. In the current study, we suggest countermeasures to reduce long stays.

\section{Methods}

\section{Definition}

We defined hospital LOS as the number of days from admission to discharge (or death). Long stay was LOS for more than 30 days. Prolonged mechanical ventilation (PMV) meant treatment with a mechanical ventilator for at least six hours daily for $>21$ consecutive days.

\section{Details of Hospital}

The Dalin Tzu Chi General Hospital is a tertiary-level teaching hospital. It has 600 acute care beds, and the intensive care unit contains 59 beds. We have a 10-bed ventilator weaning unit (respiratory care center) for PMV patients.

\section{Quality Management Center}

We established a quality management center to monitor and review patients with hospital LOS greater than 30 days. The management of long-stay patients proceeded as follows:

1) Identify long-stay patients.

2) Analyze admission and hospital course details, demographic characteristics, discharge status, and long-stay causes.
3) Identify systemic problems and clinical problems associated with long stays.

4) Develop strategies for resolving these problems.

5) Monitor the effectiveness of the strategy.

\section{Participant Details}

We performed this study on acute care wards, intensive care units, and respiratory care center of Dalin Tzu Chi hospital. We enrolled all patients consecutively admitted to the acute care wards, intensive care units, and respiratory care center between 1 January 2018 and 31 December 2018. The exclusion criteria were psychiatry patients, hospice patients, and premature babies.

\section{Data Collection}

We obtained data from the hospital's clinical information systems and medical chart review. We obtained details on long stay patient demographics, details of admission and hospital course, hospital days, duration of mechanical ventilation, and causes of long stay.

We categorized all long-stay patients according to the causes of long stays as follows: 1) PMV; 2) disease requiring hospitalization; 3) nosocomial infections; 4) iatrogenic complications; 5) delayed discharge; and 6) various causes.

\section{Data Analysis}

We expressed continuous variables as mean \pm standard deviation or median (range) and categorical variables as frequencies and percentages. We measured differences in baseline characteristics, mean long-stay days, and clinical outcomes using the Student's $t$-test for continuous variables and Pearson chi-square and Fisher's exact tests for categorical variables. We performed all statistical analyses using the statistical package SPSS for Windows (Version 17.0, SPSS, Inc., Chicago, IL, US). P-values $<0.05$ designated statistical significance.

\section{Ethics Approval}

The study conformed to the Declaration of Helsinki in 1975, revised in Hong Kong in 1989. Our study was a retrospective analysis of medical records. The study represented the lowest risk to the research subjects, and we anonymized all information before publication. The Buddhist Dalin Tzu Chi general hospital research ethics committee approved the study (approval number B10903007) and waived the informed consent requirement. 


\section{Results}

\section{Details of the Patient Cohort}

Over the study period, there were 446 long-stay patients, with a mean age of 66.7 years and $37.7 \%$ females. Patients aged more than 64 years accounted for $56.1 \%$. Figure 1 displays a view of hospital days and all long-stay patient occupied bed days. The most common departments with long stays without PMV (in order) were plastic surgery, orthopedics, radio-oncology, oncology, and neurology (Table 1). The most common departments with longer stays with PMV (in order) were chest medicine, neurosurgery, and cardiovascular. A total of 158 patients undergoing PMV accounted for 9331 hospital days (42.8\%) (Table 2). The average hospital days for patients undergoing PMV were significantly different from those of patients without PMV (59.1 days versus 43.3 days, $\mathrm{P}<0.001$ ). There were 3100 hospital days in respiratory care center where the average number of hospital days 19.6. It was impossible to avoid aggressive medical treatment of these 158 patients.

There were 109 patients for whom the cause of longer stay was disease requiring hospitalization (Table 3). The most common departments in this category (in order) were plastic surgery, orthopedics, and neurosurgery. Among plastic surgery patients, there were 14 with diabetic foot ulcers with infections requiring wound care, debridement, and repeated skin grafts during hospitalization. Among orthopedics patients, there were 18 complications from previous surgical infections. Among neurosurgery patients, all 13 suffered complications of central nervous system infections. The mean number of hospital days for neurosurgical patients was 52.5, significantly longer than for other disease requiring hospitalization $(\mathrm{P}<0.001)$.

Nosocomial infection caused 93 patients to stay in the hospital for long periods (Table 4). These infections included 33 cases of pneumonia (35.5\%), 21 cases of sepsis $(22.6 \%), 12$ urinary tract infections, nine surgical wound infections, three neutropenic fevers, three pleural empyema cases, and 12 infections at other sites. The most common departments for nosocomial infections long stay (in order) were radio-oncology and chest medicine. In radio-oncology patients, there were seven hospitalacquired cases of pneumonia. In chest medicine, there were eight hospital-acquired cases of pneumonia.

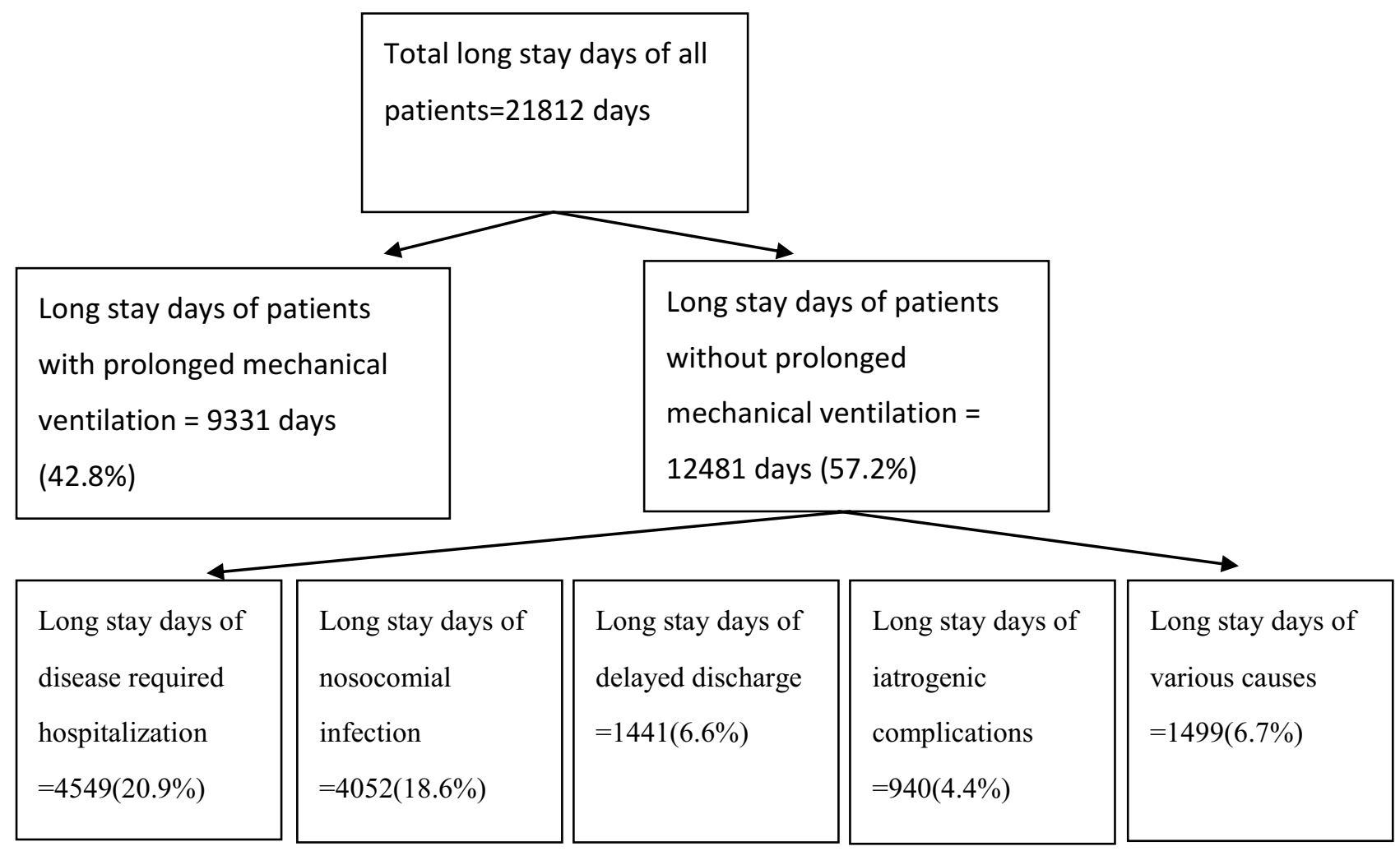

Figure I Displays a view of hospital days and all long stay patient occupied bed days. There are $2 / 8 \mid 2$ long stay days of all patients, including $933 \mathrm{I}$ days of patients with prolonged mechanical ventilation and 1248 I days of patients without prolonged mechanical ventilation. The 1248 I days of patients without prolonged mechanical ventilation, including 4549 days of diseases requiring hospitalization, 4052 days of nosocomial infection, I44I days of delayed discharge, 940 days of iatrogenic complications, and I 449 days of long stays for various causes. 
Table I The Demography of Long Stay without Prolonged Mechanical Ventilation Patients Related to Admission Sections

\begin{tabular}{|c|c|c|c|c|}
\hline Sections & $\begin{array}{c}\text { Long Stay } \\
\text { without } \\
\text { Prolonged } \\
\text { Mechanical } \\
\text { Ventilation } \\
\text { Patients } \\
\text { (No.) }\end{array}$ & $\begin{array}{c}\text { Sex } \\
\text { (M/F) }\end{array}$ & $\begin{array}{c}\text { Mean } \\
\text { Age } \\
(Y / O)\end{array}$ & $\begin{array}{c}\text { Mean } \\
\text { Hospital } \\
\text { Days }\end{array}$ \\
\hline Plastic surgery & 38 & $26 / 12$ & 63.7 & 39.3 \\
\hline Orthopedic & 34 & $24 / 10$ & 62.4 & 45.7 \\
\hline Radio-oncology & 30 & $19 / 11$ & 62.4 & 42.3 \\
\hline Hema-oncology & 29 & $14 / 15$ & 65.7 & 42.1 \\
\hline Neurology & 26 & $13 / 13$ & 69.3 & 42.8 \\
\hline Chest medicine & 24 & $16 / 8$ & 76.9 & 39.9 \\
\hline Neurosurgery & 22 & $14 / 8$ & 55.8 & 56.3 \\
\hline Gastroenterology & 18 & $11 / 7$ & 60.5 & 40.0 \\
\hline Nephrology & 18 & $8 / 10$ & 72.3 & 39.6 \\
\hline Rheumatology & 10 & $6 / 4$ & 63.4 & 42.0 \\
\hline Infection disease & 8 & $6 / 2$ & 59.7 & 41.5 \\
\hline General surgery & 8 & $\mathrm{I} / 7$ & 59.8 & 42.3 \\
\hline $\begin{array}{l}\text { Cardiovascular } \\
\text { surgery }\end{array}$ & 4 & $4 / 0$ & 40.0 & 41.0 \\
\hline Cardiovascular & 3 & $3 / 0$ & 69.6 & 40.3 \\
\hline Miscellaneous & 16 & $7 / 9$ & 52.7 & 51.1 \\
\hline
\end{tabular}

Abbreviations: No, number; Y/O, years old; M, male; F, female.

There were 20 patients for whom the cause of long stay was an iatrogenic complication, including ten surgical complications and ten medical therapy complications (Table 5). The most commonly involved department was oncology. Three cases were chemotherapy-related complications.

There were 31 patients for whom the cause of long stay was delayed discharge (Table 5). For 27 patients, there were attending physician factors. Low-income family economic support or poor home care ability after discharge caused four such delays. The most common departments with delayed discharge (in order) were radio-oncology, chest medicine, plastic surgery, and colon and rectum surgery. After careful analysis, we found that four physicians accounted for the majority.

There were 35 patients for whom the cause of long stay was various causes (Table 5). The most common department
Table 2 The Demography of Long Stay with Prolonged Mechanical Ventilation Patients Related to Admission Sections

\begin{tabular}{|c|c|c|c|c|}
\hline Sections & $\begin{array}{c}\text { Long Stay } \\
\text { with } \\
\text { Prolonged } \\
\text { Mechanical } \\
\text { Ventilation } \\
\text { Patients } \\
\text { (No.) }\end{array}$ & $\begin{array}{c}\text { Sex } \\
(M / F)\end{array}$ & $\begin{array}{c}\text { Mean } \\
\text { Age } \\
(\mathrm{Y} / \mathrm{O})\end{array}$ & $\begin{array}{c}\text { Mean } \\
\text { Hospital } \\
\text { Days }\end{array}$ \\
\hline Plastic surgery & 3 & $3 / 0$ & 62.6 & 68.3 \\
\hline Orthopedic & 10 & $7 / 3$ & 51.6 & 60.8 \\
\hline Neurology & 4 & $2 / 2$ & 73.7 & 57.7 \\
\hline Chest medicine & 63 & $38 / 25$ & 71.5 & 60.8 \\
\hline Neurosurgery & 29 & $22 / 7$ & 72.7 & 57.4 \\
\hline Gastroenterology & 5 & $5 / 0$ & 80.4 & 56.8 \\
\hline Nephrology & 4 & $3 / 1$ & 76.5 & 55.2 \\
\hline Infection disease & 8 & $5 / 3$ & 79.0 & 57.7 \\
\hline General surgery & 10 & $3 / 7$ & 69.0 & 53.5 \\
\hline $\begin{array}{l}\text { Cardiovascular } \\
\text { surgery }\end{array}$ & 5 & $3 / 2$ & 77.0. & 52.6 \\
\hline Cardiovascular & 11 & $9 / 2$ & 78.2 & 57.7 \\
\hline Miscellaneous & 6 & $5 / 1$ & 51.3 & 61.5 \\
\hline
\end{tabular}

Abbreviations: No, number; Y/O, years old; M, male; F, female.

was neurology. Sixteen patients could not go home because they received rehabilitation. Three patients on the radiooncology department stayed long to receive radiotherapy.

\section{Discussion}

Long stay with PMV was indicated in the intensive care unit when patients suffered from early respiratory failure stages. After the early stage, most patients progressed to the subacute stage when they underwent aggressive weaning from the ventilator. We could not wean the ventilator on the general ward in our hospital; we established a respiratory care center for this purpose. There were 3100 patient-days spent on the respiratory care center hospital days during the study period, meaning we created space in the intensive care unit for additional critically ill patients. Setting a ventilator weaned unit in a tertiary-level hospital is essential to reduce long stay of intensive care unit.

Diseases requiring hospitalization were the second common reason for long stays in our study. There were 31 patients admitted to treat complications of surgical 
Table 3 The Number of Long Stay Patients without Prolonged Mechanical Ventilation Related to Disease Required Hospitalization

\begin{tabular}{|l|c|c|c|}
\hline Sections & $\begin{array}{c}\text { Long Stay without } \\
\text { Prolonged } \\
\text { Mechanical } \\
\text { Ventilation } \\
\text { Patients (No.) }\end{array}$ & $\begin{array}{c}\text { Total } \\
\text { Hospital } \\
\text { Days }\end{array}$ & $\begin{array}{c}\text { Mean } \\
\text { Hospital } \\
\text { Days }\end{array}$ \\
\hline Plastic surgery & 25 & 971 & 38.8 \\
Orthopedic & 21 & 843 & 40.1 \\
Neurosurgery & 13 & 683 & 52.5 \\
Gastroenterology & 11 & 456 & 41.5 \\
Hema-oncology & 10 & 433 & 43.3 \\
Radio-oncology & 6 & 247 & 41.2 \\
Nephrology & 6 & 272 & 45.3 \\
Rheumatology & 4 & 147 & 36.8 \\
Chest medicine & 4 & 149 & 37.3 \\
Miscellaneous & 9 & 348 & 38.7 \\
Total & 109 & 4549 & 41.7 \\
\hline
\end{tabular}

Abbreviation: No, number.

Table 4 The Number of Long Stay Patients without Prolonged Mechanical Ventilation Related to Nosocomial Infection

\begin{tabular}{|l|c|c|c|}
\hline Department & $\begin{array}{c}\text { Long Stay without } \\
\text { Prolonged } \\
\text { Mechanical } \\
\text { Ventilation } \\
\text { Patients (No.) }\end{array}$ & $\begin{array}{c}\text { Total } \\
\text { Hospital } \\
\text { Days }\end{array}$ & $\begin{array}{c}\text { Mean } \\
\text { Hospital } \\
\text { Days }\end{array}$ \\
\hline Radio-oncology & 15 & 636 & 42.4 \\
Chest medicine & 12 & 447 & 37.3 \\
Nephrology & 8 & 313 & 39.1 \\
Neurosurgery & 8 & 499 & 62.3 \\
Oncology & 8 & 323 & 40.4 \\
Orthopedics & 7 & 265 & 37.9 \\
Neurology & 6 & 238 & 39.6 \\
Plastic surgery & 6 & 240 & 40.0 \\
Gastroenterology & 5 & 228 & 45.6 \\
Rheumatology & 5 & 207 & 41.4 \\
Infectious disease & 4 & 153 & 38.3 \\
Miscellaneous & 9 & 503 & 55.9 \\
Total & 93 & 4052 & 43.6 \\
\hline
\end{tabular}

Abbreviation: No, number.

infections, most of which are avoidable. Surgical systems should focus on aseptic specifications and procedures for surgery, improve preoperative preparation, and reduce postoperative infections. In patients undergoing plastic surgery, there were 14 cases of diabetic foot ulcer with infection, another cause of long stay that we can reduce. We must educate patients and families regarding the significance, care, and management of diabetic foot.
Table 5 The Number of Long Stay Patients without Prolonged Mechanical Ventilation Related to latrogenic Complications, Delayed Discharge, and Various Causes

\begin{tabular}{|c|c|c|c|}
\hline Department & $\begin{array}{c}\text { Long Stay } \\
\text { without } \\
\text { Prolonged } \\
\text { Mechanical } \\
\text { Ventilation } \\
\text { Patients (No.) }\end{array}$ & $\begin{array}{c}\text { Total } \\
\text { Hospital } \\
\text { Days }\end{array}$ & $\begin{array}{c}\text { Mean } \\
\text { Hospital } \\
\text { Days }\end{array}$ \\
\hline \multicolumn{4}{|l|}{$\begin{array}{l}\text { latrogenic } \\
\text { complications }\end{array}$} \\
\hline Oncology & 5 & 283 & 56.6 \\
\hline General surgery & 3 & 125 & 41.7 \\
\hline Orthopedics & 3 & 186 & 62 \\
\hline Chest medicine & 2 & 83 & 41.5 \\
\hline Nephrology & 2 & 76 & 38 \\
\hline Miscellaneous & 5 & 187 & 37.4 \\
\hline \multicolumn{4}{|l|}{ Delayed discharge } \\
\hline Radio-oncology & 5 & 233 & 46.6 \\
\hline Chest medicine & 5 & 240 & 48 \\
\hline Plastic surgery & 5 & 194 & 38.8 \\
\hline $\begin{array}{l}\text { Colon \& rectum } \\
\text { surgery }\end{array}$ & 4 & 139 & 34.8 \\
\hline Orthopedics & 3 & 258 & 86 \\
\hline General surgery & 2 & 65 & 32.5 \\
\hline Oncology & 2 & 85 & 42.5 \\
\hline Gynecology & 2 & 85 & 42.5 \\
\hline Miscellaneous & 3 & 142 & 47.8 \\
\hline \multicolumn{4}{|l|}{ Various causes } \\
\hline Neurology & 19 & 843 & 44.3 \\
\hline Oncology & 4 & 168 & 42 \\
\hline Radio-oncology & 3 & 100 & 33.3 \\
\hline Plastic surgery & 2 & 92 & 46 \\
\hline General surgery & 2 & 67 & 33.5 \\
\hline Miscellaneous & 5 & 229 & 45.8 \\
\hline
\end{tabular}

Abbreviation: No, Number.

Adequate antibiotic treatment, appropriate wound care, and early surgical intervention are critical for diabetic foot healing. In our hospital, this was the responsibility of the diabetes medical team. There were 45 long stays due to disease requiring hospitalization, most of which we could improve and reduce through management.

Nosocomial infection was the third most common cause of long stay in our study. Numerous studies discussed the prolongation of hospital stays attributable to nosocomial infections. ${ }^{10-13}$ More extended hospital stays generally correlate with a higher incidence of nosocomial infections. Hospital infection control centers should strictly implement control strategies to reduce 
these infections. This would include promoting infection control education, paying attention to hand hygiene management, standardizing surgical disinfection, and strengthening the protection of common nosocomial infection sites. Clinicians should administer antibiotic consumption effectively and isolate multidrug-resistant bacteria to reduce their spread. Strict infection control measures can reduce most long stays attributable to nosocomial infection.

There is no reliable definition for delayed discharge. We defined delayed discharge as discharge occurring after acute care services are no longer medically necessary for the patient. ${ }^{14,15}$ We classified the causes as physician or family factors. There were 31 long-stay cases associated with delayed discharge. After careful analysis, we found that 17 patients stayed long because of the attending physician's inactive medical behavior, primarily due to four physicians. The department director is responsible for the quality of the department's medical treatment. The department director should exert his authority to persuade the attending physicians to correct inactivity and improve the level of clinical professional ability of the department. There were four long-stay cases attributable to family factors. Many studies found that comprehensive discharge planning is essential for delayed discharge related to family factors. ${ }^{16-20}$ Hospital discharge preparation teams and social workers should address the difficulties faced by families and patients after discharge. All long-stay cases due to delayed discharge are preventable.

Iatrogenic complications caused 20 long stays. No study addressed the yearly number of iatrogenic complications causing long stays. We believe that our 20 cases represent a small number. Steel et al reported 76 patients with significant complications, and the average total LOS was 19.3 days..$^{21}$ In our series, we only considered longstay patients of iatrogenic complications, and the average hospital day was 47.0 days.

The most common department involving various causes of long stays was neurology. There were 16 patients on neurology who could not go home because they received rehabilitation. There are three ways to solve this problem: 1) we should arrange for outpatient rehabilitation; 2) we should establish a rehabilitation ward to open beds on the acute care ward; and 3) we should transfer patients to other hospital rehabilitation wards. Three patients stayed long to receive radiotherapy, all of whom could receive outpatient therapy.
After analyzing the data, we found that 188 (42.1\%) of patients with long stays were inevitable; nevertheless, we can reduce this number.

\section{Limitations}

This study occurred at one tertiary-level teaching hospital. Our patients' characteristics were not similar to those of other tertiary-level teaching hospitals; therefore, one should use our results for reference only. According to the hospital's patient population and medical culture, administrators can adjust the design to establish a method that fits the hospital medical system and then carry out a long-stay patient study.

\section{Conclusion}

Prolonged mechanical ventilation patients progressed to the weaning center when they underwent aggressive weaning from the ventilator, meaning we created space in the intensive care unit for additional critically ill patients. Setting a ventilator weaned unit in a tertiary-level hospital is essential to reduce long stay of intensive care unit. As many as $42 \%$ of long-stay patients are preventable using aggressive management strategies.

\section{Data Sharing Statement}

The datasets used and/or analyzed during the current study are available from the corresponding author on reasonable request.

\section{Ethics Approval}

The project was approved by Buddhist Dalin Tzu Chi general hospital research ethics committee. (Approved IRB No.: B10903007)

\section{Consent for Publication}

Not applicable.

\section{Author Contributions}

All authors made substantial contributions to conception and design, acquisition of data, or analysis and interpretation of data; took part in drafting the article or revising it critically for important intellectual content; agreed to submit to the current journal; gave final approval of the version to be published; and agree to be accountable for all aspects of the work.

\section{Funding}

There was no funding in this study. 


\section{Disclosure}

The author declares no competing interests.

\section{References}

1. Polito A, Combescure C, Levy-Jamet Y, et al. Long-stay patients in pediatric intensive care unit: diagnostic-specific definition and predictors. PLoS One. 2019;14(10):e0223369. doi:10.1371/journal. pone.0223369

2. Miura S, Fukushima M, Kurosawa H, et al. Epidemiology of long-stay patients in the pediatric intensive care unit: prevalence, characteristics, resource consumption and complications [published online ahead of print, 2020 Apr 17]. Z Gesundh Wiss. 2020:1-9. doi:10.1007/s10389-020-01282-3.

3. Ping Kirk AH, Sng QW, Zhang LQ, et al. Characteristics and outcomes of long-stay patients in the pediatric intensive care unit $J$ Pediatr Intensive Care. 2018;7(1):1-6. doi:10.1055/s-00371601337

4. Zhong S, Guo H, Wang Y, et al. The experience of long-stay patients in a forensic psychiatric hospital in China: a qualitative study. $B M C$ Health Serv Res. 2019;19(1):617. doi:10.1186/s12913-019-4458-6

5. Huband N, Furtado V, Schel S, et al. Characteristics and needs of long-stay forensic psychiatric inpatients: a rapid review of the literature. Int $J$ Forensic Ment Health. 2018;17(1):45-60. doi:10.1080/14999013.2017.1405124

6. Formiga F, Chivite D, Manito N, et al. Admission characteristics predicting longer length of stay among elderly patients hospitalized for decompensated heart failure. Eur J Intern Med. 2008;19 (3):198-202. doi:10.1016/j.ejim.2007.09.007

7. Campbell SE, Seymour DG, Primrose WR. ACMEPLUS Project. A systematic literature review of factors affecting outcome in older medical patients admitted to hospital. Age Ageing. 2004;33:110-115. doi:10.1093/ageing/afh036

8. Maguire PA, Taylor IC, Stout RW. Elderly patients in acute medical wards: factors predicting length of stay in hospital. $\mathrm{Br}$ Med $\mathrm{J}$ 1986;292:1251-1253. doi:10.1136/bmj.292.6530.1251

9. O'Sullivan K, Martensson J, Robbins R, et al. Epidemiology of long-stay patients in a university teaching hospital. Intern Med J. 2017;47:513-521. doi:10.1111/imj.13379

10. Manoukian S, Stewart S, Dancer S, et al. Estimating excess length of stay due to healthcare-associated infections: a systematic review and meta-analysis of statistical methodology. J Hosp Infect. 2018;100 (2):222-235. doi:10.1016/j.jhin.2018.06.003
11. Arefian H, Hagel S, Heublein S, et al. Extra length of stay and costs because of health care-associated infections at a German university hospital. Am J Infect Control. 2016;44(2):160-166. doi:10.1016/j. ajic.2015.09.005

12. Schulgen G, Kropec A, Kappstein I, et al. Estimation of extra hospital stay attributable to nosocomial infections: heterogeneity and timing of events. J Clin Epidemiol. 2000;53(4):409-417. doi:10.1016/ s0895-4356(99)00182-1

13. De Angelis G, Murthy A, Beyersmann J, et al. Estimating the impact of healthcare-associated infections on length of stay and costs. Clin Microbiol Infect. 2010;16(12):1729-1735. doi:10.1111/j.14690691.2010.03332.x

14. Costa AP, Poss JW, Peirce T, et al. Acute care inpatients with long-term delayed-discharge: evidence from a Canadian health region. BMC Health Serv Res. 2012;12:172. doi:10.1186/14726963-12-172

15. Black D, Pearson M. Average length of stay, delayed discharge, and hospital congestion. BMJ. 2002;325(7365):610-611. doi:10.1136/ bmj.325.7365.610

16. Hyde CJ, Robert IE, Sinclair AJ. The effects of supporting discharge from hospital to home in older people. Age Ageing. 2000;29 (3):271-279. doi:10.1093/ageing/29.3.271

17. Preyde M, Macaulay C, Dingwall T. Discharge planning from hospital to home for elderly patients: a meta-analysis. J Evid Based Soc Work. 2009;6(2):198-216. doi:10.1080/15433710802686898

18. Shepperd S, McClaran J, Phillips CO, et al. Discharge planning from hospital to home. Cochrane Database Syst Rev. 2010;(1):CD000313. doi:10.1002/14651858.CD000313

19. Luziani M, Ronald Lagoe R, Littau S. Reducing Hospitalization for Long Stay Patients. Case Rep Clin Med. 2017;6:221-226. doi:10.4236/crcm.2017.68023

20. Hesselink G, Schoonhoven L, Barach P, et al. Improving patient handovers from hospital to primary care: a systematic review. Ann Intern Med. 2012;157(6):417-428. doi:10.7326/0003-4819-1576-201209180-00006

21. Steel K, Gertman PM, Crescenzi C, et al. Iatrogenic illness on a general medical service at a university hospital. 1981. Qual Saf Health Care. 2004;13(1):76-80. doi:10.1136/qshc.2002.003830
International Journal of General Medicine

\section{Publish your work in this journal}

The International Journal of General Medicine is an international, peer-reviewed open-access journal that focuses on general and internal medicine, pathogenesis, epidemiology, diagnosis, monitoring and treatment protocols. The journal is characterized by the rapid reporting of reviews, original research and clinical studies across all disease areas. The manuscript management system is completely online and includes a very quick and fair peer-review system, which is all easy to use. Visit http://www.dovepress.com/ testimonials.php to read real quotes from published authors. 